\title{
Experiências vividas no planejamento de cursos instrumentais: percursos de transformação numa abordagem heurístico-fenomenológico-hermenêutica
}

Orlando Vian Jr.

Universidade Federal do Rio Grande do Norte

RESUMO: A partir do conceito de contínuo experiencial (DEWEY, 1938/1997), relato experiências vividas (van MANEN, 1990) no planejamento de cursos instrumentais de produção oral com base em gêneros do discurso para alunos iniciantes, mostrando o meu percurso profissional e minha transformação de um professor de inglês em course designer, a partir do planejamento de nove cursos instrumentais desenvolvidos em um período de cinco anos. Adoto, para relatar tais experiências, uma abordagem de cunho heurístico-fenomenológico-hermenêutico, com base na descoberta e, a partir da colocação do fenômeno de planejar cursos 'entre parênteses' (HUSSERL, 1973, 2000), interpreto-o para atingir a essência do fenômeno.

PALAVRAS-CHAVE: experiências vividas, planejamento de cursos instrumentais, abordagem heurístico-femomenológico-hermenêutica

\section{Histórias de planejamento de cursos instrumentais}

Retomo, neste texto, o tema abordado em texto anterior (VIAN Jr, 2002 ), ${ }^{1}$ no qual tomei como objeto a minha própria experiência com base em meu contínuo experiencial (DEWEY, 1938/1997) e, a partir dele, relato experiências vividas (van MANEN, 1990) no planejamento de cursos instrumentais de produção oral com base em gêneros do discurso para alunos iniciantes, mostrando o meu percurso profissional e minha transformação de um professor de inglês em course designer, a partir do planejamento de nove cursos instrumentais desenvolvidos em um período de cinco anos, de 1995 a 2000.

Utilizo, para a compreensão do fenômeno de planejar esses cursos, a pesquisa qualitativa de cunho heurístico-fenomenológico-hermenêutico, para a qual a descrição fenomenológica e a interpretação das significações que

\footnotetext{
${ }^{1}$ Este texto compõe-se de excertos de minha tese de doutorado (Vian Jr, 2002). Para detalhamentos sobre quaisquer aspectos aqui apresentados, remeto o leitor ao trabalho original, disponível em http://www.pucsp.br/pos/lael/lael-inf/def_teses.html.
} 
emergiram das experiências revelam três momentos distintos, partindo de um professor que enfrenta dificuldades em encontrar materiais que atendam às necessidades de seus alunos, passando por um profissional preocupado com as teorias que embasam sua prática e chegando a um course designer que desempenha a tarefa de planejar os cursos que ministra.

A interpretação aponta as experiências vividas e seu mapeamento como os pontos-chave para a compreensão do fenômeno de se planejar cursos de inglês instrumental, trazendo consigo reflexões sobre a importância de diversos conhecimentos e sua utilização como fonte de significações para o planejamento de cursos.

De forma a proporcionar uma visão geral dos cursos planejados, apresento de forma esquemática, no Quadro 1, cada um dos cursos, o ano em que foram elaborados, sua carga horária e o número de alunos em cada um deles, para facilitar, num momento posterior, o resgate dessas experiências e a apreensão de seus significados.

\section{QUADRO 1}

Resumo dos cursos planejados

\begin{tabular}{|l|c|c|c|}
\hline \multicolumn{1}{|c|}{ Curso } & $\begin{array}{c}\text { Ano de } \\
\text { elaboração }\end{array}$ & $\begin{array}{c}\text { Carga } \\
\text { horária }\end{array}$ & Alunos \\
\hline Inglês para copeiras & 1995 & 64 horas & 9 \\
Inglês para secretárias e recepcionistas & 1996 & 64 horas & 24 \\
Inglês para reuniões & 1998 & 24 horas & 24 \\
Inglês para atendimento a turistas no câmbio & 1998 & 24 horas & 14 \\
Inglês para atendimento telefônico a estrangeiros & 1998 & 24 horas & 26 \\
Inglês para entrevistas & 1999 & 20 horas & 2 \\
Inglês para garçons & 2000 & 60 horas & 12 \\
Inglês para seguranças & 2000 & 60 horas & 8 \\
Inglês para governantas & 2000 & 60 horas & 12 \\
\hline
\end{tabular}

A visualização dos cursos em conjunto, por outro lado, possibilitou-me o maior desenvolvimento de minha percepção como professor, como course designer, como pesquisador e como ser humano; possibilitou também o desenvolvimento de minha sensibilidade e ainda uma exploração do meu próprio selfatravés das experiências vividas. Através delas, explorei os pensamentos e emoções suscitados e, inerentes a eles, novos meios para a interpretação de seus significados e suas repercussóes em minha vida presente, envolvendo, como aponta Moustakas (1990, p.11), a procura, o diálogo comigo mesmo e a autodescoberta. 
Reforço a relação existente entre o trabalho de ensinar inglês e de planejar cursos instrumentais, que agora apresento de forma sucinta, emergindo daí o seu caráter heurístico: uma conexão biográfica com o fenômeno que me propus a estudar (MOUSTAKAS, 1990, p.14).

Faço ainda a distinção entre coletar material experiencial e analisar esse material. Como sinaliza van Manen (1990, p.63), esses dois atos não são separáveis e devem ser vistos como parte de um mesmo processo. Entretanto, no relato aqui apresentado, eles estão sendo considerados como dois diferentes estágios de um mesmo processo, daí o fato de eu ter, no Quadro 1, apresentado os cursos que compreendem o meu contínuo experiencial (DEWEY, 1938/ 1997 , p. 33) e que funcionam como o material experiencial (van MANEN, 1990, p. 63) para a pesquisa desenvolvida e aqui relatada.

\section{Uma abordagem heurístico-fenomenológico-hermenêutica}

Ao abordar experiências vividas pelo prisma heurístico-fenomenológicohermenêutico, um dos primeiros pontos a se considerar está relacionado ao fato de que essa abordagem será ao mesmo tempo descritiva e interpretativa, obedecendo ao fluxo natural dos fatos que compreendem o fenômeno em estudo: observo como as coisas aparecem e deixo-as falarem por si mesmas de forma a poder interpretá-las (van Manen, 1990, p.180).

A percepção sobre o planejamento dos cursos relatados foi sendo desenvolvida a partir de um processo heurístico que me permitiu, num primeiro momento, com base na descrição dos cursos, reviver experiências a eles relacionadas e, também, vislumbrar novos elementos que poderiam fornecer-me subsídios para uma melhor compreensão do fenômeno sob estudo.

Tais experiências, portanto, levaram-me a considerar a possibilidade de se desenvolver uma pesquisa a partir de uma abordagem que pudesse articular os conceitos filosóficos com os quais lidava e associá-los às minhas próprias experiências, às descobertas a elas subjacentes e às essências de tais experiências.

Os princípios conceituais que fundamentam este trabalho tomam por base a fenomenologia de Husserl $(1973,2000)$, que enfatiza a subjetividade e a descoberta das essências das experiências e, ao mesmo tempo, fornece uma metodologia sistemática para que dela se derivem conhecimentos (MOUSTAKAS, 1994, p. 45). Ao realizarmos a tarefa descritiva de nossa experiência, "vemos surgir diante de nós verdadeiros mundos de fatos” (HUSSERL, 2001, p. 59). Há que se acrescentar, ainda, principalmente a partir do proposto por van Manen 
(1990) que, além dessa perspectiva filosófica proposta por Husserl, existe uma compreensão prática do que seja fenomenologia, que pode ser obtida apenas desenvolvendo-a ativamente (van MANEN, 1990, p. 8), ou seja, a partir da própria descrição da experiência, de forma prática, e não com base em teorizações. Abstraímos o fazer fenomenológico através da experiência.

A fenomenologia culmina ao se atingir a síntese criativa e a essência do fenômeno colocado entre parênteses, que é obtida por meio da descrição das experiências. Como meu objetivo aqui é apresentar a síntese criativa e a essência do fenômeno em si, não apresentarei a descrição das experiências, inclusive por restrições de espaço. Remeto o leitor, como já apontei na primeira nota de rodapé, para o trabalho mais amplo, no qual são encontradas as descrições das experiências (VIAN Jr., 2002), assim como ao trabalho de van Manen (1990) sobre a pesquisa com experiências vividas e, sem dúvida, ao projeto mais amplo da fenomenologia de Husserl $(1973,2000)$ e seus seguidores.

O objetivo aqui está na utilização da heurística, da fenomenologia e da hermenêutica numa abordagem aplicada à pesquisa em Lingüística Aplicada, mostrando a aplicação semiótica de tais métodos com base nas experiências vividas relatadas de forma escrita e que, conforme preceituada por van Manen (1990, p. 8-13), pode ser resumida como:

(i) o estudo da experiência vivida;

(ii) a explicação de fenômenos como se apresentam à consciência;

(iii) o estudo das essências;

(iv) a descrição dos significados experienciais que vivemos;

(v) o estudo científico dos fenômenos;

(vi) a prática detalhada do pensamento;

(vii) a busca pelo que significa ser humano e,

(viii) uma atividade poética.

Em suma: ao adotar uma postura heurístico-fenomenológicohermenêutica, a ênfase está no significado da experiência vivida, e, portanto, explicitamente relatada na primeira pessoa. A coleta de dados é baseada na experiência, realizada sem um modelo de análise preestabelecido, sem submetê-los à interpretação ou a qualquer categorização, pois o foco é a qualidade das experiências vividas. Por se tratar de uma pesquisa qualitativa, a qualidade dessas experiências é obtida pelo texto todo das descrições realizadas, que é lido e relido para que faça sentido e dele se retirem os significados à luz 
do questionamento formulado. É importante reforçar que a descrição, do modo como é trabalhada pelo fenomenólogo, "é um protocolo que se limita a descrever o visto, o sentido, a experiência como vivida pelo sujeito" (BICUDO, 2000, p. 77) e, portanto, é exposta por meio da linguagem.

Essa premissa permitiu-me observar o fenômeno em sua forma plena e da maneira como era manifestado, além de proporcionar a experiência de revivê-lo ao recontá-lo, possibilitando, assim, uma compreensão maior dos significados que dele emergiam, justificando, assim, a opção pela heurística.

A forma como a essência do fenômeno e sua síntese criativa são apresentadas e interpretadas aqui representam o resultado das experiências revividas e somente emergiram a partir da interação com os dados, da revisitação, do recontar, do reviver as experiências pessoais, caracterizando seu prisma fenomenológico.

A partir dessas experiências, pude interpretá-las, o que me levou, por conseguinte, a uma conscientização maior de minhas percepções, bem como das diversas influências que elas podem exercer em minhas interpretaçōes, trazidas por fatores como os pressupostos teóricos que me guiaram ou pelas novas ressignificações de minhas experiências, uma tarefa, portanto, hermenêutica.

Neste ponto, é importante que eu aponte também para a importância da reflexão no processo heurístico pelo qual passei, principalmente os conceitos relacionados à reflexão propostos por Schön (1983, 1987, 1992a, 1992b) e a preocupação do autor em associar o conceito de reflexão à ação. $\mathrm{O}$ fato de refletir sobre a minha prática de sala de aula e também sobre o meu trabalho no planejamento dos cursos, tanto em sua execução, durante a ação, quanto posteriormente, durante a elaboração de minha tese e agora, ao elaborar este texto, sobre a ação, proporcionaram-me uma maior compreensão do fenômeno em estudo.

Para discutir os dados de meu percurso profissional, apresentei, em meu texto de 2002, nove cursos ${ }^{2}$ e optei pela análise detalhada apenas do curso para porteiros e seguranças. Essa escolha se deveu, em primeiro lugar, ao fato de ser, do ponto de vista temporal, o último curso situado em meu contínuo experiencial, o último curso que planejei, o que pode me permitir observar o fenômeno posto 'entre parênteses' (HUSSERl, 1973, 2000) em retrospectiva,

\footnotetext{
${ }^{2}$ As experiências relacionadas a cada um dos nove cursos planejados são descritas integralmente no capítulo 3 de Vian Jr (2002).
} 
possibilitando estabelecer relações entre esse curso e os demais planejados anteriormente a ele. Em segundo lugar, pelo fato de eu ter sido também o professor desse curso, pois o curso para garçons e o curso para governantas foram ministrados por duas colegas de trabalho sob minha supervisão.

O curso para porteiros e seguranças foi escrito especificamente para um hotel cinco estrelas na cidade de São Paulo pertencente a uma grande rede internacional de hotéis. A necessidade da empresa, manifestada pela representante do departamento de recursos humanos, era a de que os funcionários pudessem desempenhar as funções relativas à área de atuação e nas quais a língua inglesa fosse necessária.

A partir dos conteúdos do curso elaborado para seguranças, analiso tanto os fatores que me guiaram em sua elaboração como os seus conteúdos e o porquê de seu desenvolvimento para que eu possa explorar as 'unidades de significação' que emergiram dessa tarefa. Haverá, por conseguinte, um diálogo entre a prática de se planejar cursos de línguas e sua inter-relação com os pressupostos teóricos relacionados ao planejamento e elaboração de materiais e ao ensino de línguas como um todo e ao ensino instrumental mais especificamente, bem como fatores relacionados a outros cursos planejados, que possam fornecer subsídios para um maior esclarecimento sobre o tópico.

Ressalto ainda que a forma como apresento e analiso os dados é apenas uma dentre diversas outras possibilidades de análise, pelo simples fato de eu analisar uma experiência vivida, ou seja, utilizo uma metodologia heurísticofenomenológico-hermenêutica para compreender como o fenômeno de planejar cursos ocorre à 'minha' consciência. Outros pesquisadores utilizando os mesmos dados irão analisá-los de maneira diferente, de acordo com suas próprias experiências e percepções.

Os dados apresentados em texto anterior (VIAN Jr, 2002, capítulo 4), compreendem a descrição dos aspectos envolvidos no planejamento do último curso do contínuo experiencial que descrevo. Em relação à estrutura das unidades desse curso, teço considerações sobre os seguintes itens envolvidos no planejamento do curso em questão: o conhecimento prévio e os objetivos do curso; as práticas orais: da acuidade (accuracy) à fluência (fluency) e como são estruturadas e desenvolvidas, divididas em práticas controladas, práticas menos controladas e práticas livres; apresento elementos extralingüísticos e paralingüísticos pertinentes ao ensino da linguagem oral; elementos relacionados às auto-avaliações propostas pelo curso; a importância e a influência das diferenças individuais no aprendizado de línguas, onde abordo 
questôes relacionadas à conscientização, auto-estima, identidade, ansiedade, estratégias de aprendizagem e estilos de aprendizagem; discuto como são organizadas as revisóes, tanto das funçóes quanto do vocabulário e dos itens conversacionais; finalmente trato das avaliaçôes, tanto das orais quanto das escritas.

A partir das consideraçôes sobre cursos como um todo e sobre o planejamento e a elaboração do curso para porteiros e seguranças, apresento, como resultado, a minha síntese criativa (MOUSTAKAS, 1990), a minha busca pelos significados que emergiram dessas experiências, objetivando assim vislumbrar a estrutura do fenômeno que procurei explicar.

Reitero que o ponto de partida para uma investigação fenomenológica é a natureza do que se vai investigar, logo, o início do trabalho situa-se numa interrogação. E, para que essa pergunta seja respondida, o pesquisador fenomenólogo parte em busca de respostas em descrições de suas experiências vividas, com as quais trabalha como forma de familiarizar-se com os textos que descrevem tais experiências.

Essas descriçōoes possibilitam a interpretação - uma tarefa da hermenêutica (CORETH, 1973; GADAMER, 1983; HEKMAN, 1986; RICOUER, 1989; SCHLEIERMACHER, 2001) - do fenômeno e colocam em evidência significados, a partir dos quais obtêm-se unidades de significação para que, finalmente, possa se chegar a uma análise da estrutura do fenômeno.

Podemos estabelecer, dessa forma, os seguintes momentos do método da análise qualitativa do fenômeno estudado:

(1) descrição das experiências vividas relacionadas ao fenômeno;

(2) leitura das descrições para evidenciar os significados da descrição;

(3) busca de unidades de significado;

(4) análise da essência do fenômeno.

Ainda no método fenomenológico (MASINI, 1989; REZENDE, 1990; MARTINS, 1992; MOUSTAKAS, 1994; LESTER, 1999; BICUDO, 2000; MOREIRA, 2002), uma vez feita a redução fenomenológica, o próximo passo é interpretar o fenômeno da maneira como ele se apresenta à consciência, buscando a significação que se esconde por trás da significação literal.

Na pesquisa heurística (PUCHKIN, 1976; MOUSTAKAS, 1990; KLEINING; WITT, 2000, 2001), por seu turno, após os processos de envolvimento inicial, de imersão, de incubação e de iluminação, ocorrem as fases seguintes que compreendem a explicação e a síntese criativa. O objetivo é olhar retrospectivamente para as fases anteriores, vislumbrando possíveis 
explicações para as suas ocorrências, donde emergem significações que sintetizam de forma criativa o caminho percorrido pelo sujeito envolvido na pesquisa. É, sobretudo, uma atividade poética (MARTINS, 1992).

A síntese criativa e a essência do fenômeno que apresentarei a seguir, portanto, tentam, a partir do prisma heurístico-fenomenológico-hermenêutico, interpretar as minhas próprias experiências vividas relacionadas à tarefa de se planejar cursos instrumentais, bem como buscar os significados que emergem dessa tarefa para que se entenda a estrutura do fenômeno de se planejar tais cursos.

Ao analisar retrospectivamente o meu percurso profissional a partir de meu contínuo experiencial (DEWEY, 1938/1997), e através das diversas histórias revividas e recontadas, percebemos que um outro conteúdo, impregnado de diversos significados e de muitas significações, permeia tudo o que até então foi exposto: o conteúdo da minha vida profissional em um dado período de tempo.

Ao fazer esse retorno, após meses de hibernação, de leituras teóricas e práticas sobre experiências vividas, sobre narrativas de vida e sobre pesquisas fenomenológicas, foi possível delinear o meu contínuo experiencial (DEWEY, 1938/1997) e, principalmente pela volta aos meus dados e às descrições dos cursos, bem como às histórias de vida a eles associadas, os fatos passaram a assumir uma significação mais clara: a minha carreira como professor havia sofrido mudanças significativas durante o percurso.

Para compreender essas mudanças e como parte de meu processo heurístico, realizo aqui o processo de síntese criativa (MOUSTAKAS, 1990, p.31), cujo objetivo é a explicação dos significados e detalhes da experiência como um todo.

\section{A síntese criativa}

Ao observar o meu percurso, principalmente através do material experiencial que utilizei para responder à pergunta de pesquisa (Qual a natureza das experiências envolvidas no planejamento de cursos instrumentais de produção oral com base em gêneros do discurso para o ensino de inglês em contextos profissionais?), bem como os desafios surgidos no caminho e o conhecimento que adquiri ao vivenciar o processo, posso visualizá-lo através de minha síntese criativa, que se configurou através da poesia. Os conteúdos dessa síntese retratam os passos do meu caminho profissional e as dificuldades encontradas e me auxiliam, ao mesmo tempo, a encontrar as unidades de significação presentes em minha experiência. 
Após realizar diversas releituras da descrição dos cursos que havia planejado com o objetivo de compreender o fenômeno que estudo, fui familiarizando-me cada vez mais com os dados e tendo uma visão cada vez mais detalhada de minha própria personalidade e dos papéis desempenhados nos diversos contextos.

Essas releituras guiaram-me também na busca pela significação das experiências vividas relacionadas a cada uma das tarefas desenvolvidas ao planejar cada um dos nove cursos que compõem o meu contínuo experiencial. Em texto anterior (VIAN Jr., 2002), dedico o capítulo 4 ao detalhamento das experiências relativas ao curso para porteiros e seguranças como forma de ilustrar os aspectos envolvidos em seu planejamento, trazendo consigo as experiências a eles vinculadas. Nessas idas e vindas, pude, aos poucos, perceber que a minha experiência profissional podia ser dividida em três momentos distintos.

Para que essas descobertas fiquem claras ao leitor, reapresentarei os cursos e seu ano de elaboração com o objetivo de apresentar os diferentes momentos em meu percurso, uma vez que a percepção dos três momentos divide, conseqüentemente, minha carreira em três fases. Os itens em negrito no Quadro 2 marcam a passagem para uma nova fase.

QUADRO 2

Os cursos planejados e os momentos de significação

\begin{tabular}{|l|c|}
\hline \multicolumn{1}{|c|}{ Curso } & Ano de elaboração \\
\hline Inglêspara copeiras & 1995 \\
Inglês para secretárias e recepcionistas & 1996 \\
\hline Inglês para reunióes & 1998 \\
Inglês para atendimento a turistas no câmbio & 1998 \\
Inglês para atendimento telefônico a estrangeiros & 1998 \\
\hline Inglês para entrevistas & 1999 \\
Inglês para garçons & 2000 \\
Inglêspara seguranças & 2000 \\
Inglêspara governantas & 2000 \\
\hline
\end{tabular}

Após depreender esses significados da minha experiência, passei a buscar elementos que pudessem auxiliar-me na interpretação das significações de cada um desses momentos. 
Cada um deles estava associado a um significado que poderia ser depreendido a partir das experiências a eles relacionadas, principalmente no que se refere ao meu desenvolvimento profissional e ao meu relacionamento com o meio acadêmico e com teorias de ensino-aprendizagem. Mais ainda: no contato diário com o mundo educacional, pois as minhas experiências de ensino eram desenvolvidas em três contextos distintos: escolas de idiomas, o meio acadêmico e empresas nas quais eu ensinava inglês.

Esses momentos, por seu turno, possuíam uma característica marcante e, ao buscar o significado de cada um deles, pude facilmente associá-los a poemas.

As associações dos significados desses momentos aos poemas ocorreram após a leitura de Bruner (1997), que me despertou ainda mais para essa busca. Ao mesmo tempo, essas associações sintetizavam de maneira metafórica os meus percursos na elaboração e também no ensino dos cursos.

Como mencionei, realizo essa significação através de poemas e pretendo, com cada um deles, retratar o meu percurso profissional e, a partir dele, resgatar diversos elementos apresentados até aqui, atribuindo-lhes significaçóes.

\section{(i) Primeiro momento: uma pedra no meio do caminho}

O curso para copeiras e o curso para secretárias e recepcionistas foram desenvolvidos no período de um ano, que compreende o primeiro momento de meu percurso profissional.

A percepção que tenho, hoje, é a de um professor de inglês instrumental preocupado com questôes de planejamento de materiais didáticos e que, à primeira vista, e talvez pela própria imaturidade como profissional de ensino instrumental, não encontra no mercado materiais adequados ao seu contexto de ensino e que possam satisfazer as necessidades apresentadas pelos alunos.

Ao refletir sobre esses papéis, no entanto, percebo que eu não me via, ainda, como um professor de inglês instrumental, mas simplesmente como um professor que tem como tarefa desenvolver um curso de inglês para fins específicos, mas que, entretanto, não o considera como instrumental, apenas um curso de inglês.

No momento em que não encontro materiais que atendam a essas necessidades, começo a perceber a especificidade do trabalho que desenvolvo e a necessidade de buscas mais amplas e em fontes mais precisas, como o meio acadêmico e livros teóricos sobre o ensino de línguas para fins específicos. 
Esses dois cursos, portanto, são marcados pelas pedras que encontro em meu caminho, que representam as dificuldades em relação à inexistência de materiais no mercado, cuja significação é facilmente depreendida a partir do poema de Carlos Drummond de Andrade (1974) a seguir:

No meio do caminho tinha uma pedra tinha uma pedra no meio do caminho tinha uma pedra no meio do caminho tinha uma pedra.

Nunca me esquecerei desse acontecimento na vida de minhas retinas tão fatigadas. Nunca me esquecerei que no meio do caminho tinha uma pedra tinha uma pedra no meio do caminho no meio do caminho tinha uma pedra.

Há, nessa fase, uma grande insatisfação, pois o que verifico é uma ausência de materiais didáticos que ensinassem a produção oral para principiantes, o que me obrigava a conjugar diversos materiais existentes no mercado e adaptá-los às necessidades dos aprendizes.

Os cursos planejados, portanto, tinham a aparência de uma 'colcha de retalhos', por apresentarem uma certa inconsistência do ponto de vista conteudístico, obrigando não só a mim, mas também aos professores com os quais eu trabalhava, que estivéssemos constantemente desenvolvendo atividades que tornassem o material publicado e utilizado como base mais direcionado às atividades da empresa e às necessidades dos alunos. $\mathrm{O}$ trabalho consistia principalmente em adaptar atividades muito gerais, uma vez que haviam sido escritas por estrangeiros em países falantes do idioma e estávamos ministrando o curso em um país onde a língua era aprendida como língua estrangeira. Portanto, além do distanciamento sócio-histórico, tínhamos também o distanciamento geográfico e, principalmente, o distanciamento cultural.

A partir dessas experiências, minha percepção começou a mudar e comecei a vislumbrar o papel diferenciado que passara a exercer, pois estava além do professor que somente ministra suas aulas. A questão de preparar o meu próprio material me incomodava e foi nessa época que passei a freqüentar o curso para professores de inglês instrumental na Pontifícia Universidade Católica de São Paulo.

Embora eu houvesse encontrado diversas respostas no curso de inglês instrumental, muitas delas não resolviam o meu problema, que era ensinar iniciantes. 
O curso seguinte, Inglês para reuniōes, foi ministrado a alunos de nível intermediário. Logo meus problemas em relação às dificuldades de se ensinar o oral para principiantes continuava sem solução. Porém, nessa passagem, enquanto ministrava o curso para reuniões, minhas expectativas sobre o ensino de gêneros puderam ser saciadas, pois pude, nesse curso, testar diversas das minhas hipóteses sobre o papel dos gêneros do discurso no ensino instrumental.

O curso de inglês para reuniões, portanto, funciona como um divisor de águas, um rito de passagem para uma nova fase profissional, principalmente por apresentar inovaçóes teóricas e práticas em minha experiência.

A partir desse curso, o meu papel como course designer e como profissional de ensino instrumental sofreu uma sensível mudança e passei a dar maior importância para o ensino baseado em gêneros do discurso. $\mathrm{O}$ mesmo aconteceu com os alunos, pois, embora não tenham tido contato com a terminologia lingüística, desenvolveram diversas atividades a partir do gênero e do registro a partir da perspectiva sistêmico-funcional de Halliday (1985), e relataram suas percepções dessas mudanças, principalmente a questão da maior conscientização de seu papel social no evento comunicativo (cf. VIAN Jr, 2003).

Um fato significativo é a maneira como nomeio os cursos. Os cursos que compóem esse primeiro momento têm como foco a profissão das pessoas que dele participariam: inglês para copeiras, inglês para secretárias e recepcionistas. Esse fato revela também a minha visão da língua e da profissão: eu via a língua como algo mecânico a ser utilizado pelo profissional, talvez daí o fato de nomear os cursos a partir da função dos participantes.

A minha busca, a partir desse momento, está relacionada com a preocupação em tirar as pedras do caminho.

\section{(ii) Segundo momento: a ponte}

Esse segundo momento de meu percurso profissional apresenta um grande avanço do ponto de vista do planejamento dos cursos e de minha própria experiência como professor e como course designer.

Um dos fatos em minha vida acadêmica que marcam a passagem de uma fase para a outra foi a defesa de minha dissertação de mestrado, ocorrida em agosto de 1997. O cunho teórico desenvolvido em meu trabalho (VIAN Jr., 1997), no qual pesquisei as origens do conceito de gênero e as diversas correntes teóricas surgidas a partir de então, levaram-me a ter uma visão mais apurada do papel do profissional em ensino instrumental, associado ao fato 
de ter uma visão teórica mais abrangente, a partir do contato estabelecido entre as diversas teorias sobre gêneros do discurso e suas aplicações pedagógicas.

O curso para reunióes funciona, em minha vida profissional, e também em relação aos cursos em meu contínuo experiencial, como minha iniciação nessa nova fase, em que todas as minhas atitudes como professor, como profissional de ensino instrumental e como ser humano foram revistas, desde a análise de necessidades, passando pelo planejamento do curso e pelas aulas propriamente ditas.

Os três cursos que sucedem o curso para reuniôes fazem parte desse segundo momento em meu percurso profissional. A característica principal nessa fase é o início do distanciamento dos materiais publicados e uma preocupação maior com a produção do material que atendesse às necessidades específicas do aprendiz. É quando descubro o 'outro' em mim mesmo.

Nessa fase, começo a ver o 'outro', o que pode significar ver-me 'de fora', favorecendo a minha auto-percepção. Percebo que, ao eliminar algumas pedras de meu caminho, outras ainda persistem. Embora, dessa vez, essas pedras representem crenças e dificuldades ainda existentes.

Ao olhar para o outro, no caso, meus alunos, percebo que meu trabalho deve ser totalmente voltado para eles, que todas as novas teorias de que tomo conhecimento devem ser aplicadas aos cursos, numa constante preocupação em auxiliar os alunos no aprendizado do idioma. Percebo que em momento algum existe a preocupação comigo mesmo, com minhas crenças, com minhas necessidades, com minhas percepções, com meus problemas pessoais. A sala de aula deve ser o ambiente sagrado onde o conhecimento que busquei em diversas fontes seja passado aos alunos; funciono apenas como uma ponte entre o conhecimento e os alunos. Olhando por um prisma crítico, posso dizer que me encontro nas 'zonas intermediárias', representada pela minha angústia em tentar atender as necessidades dos alunos de qualquer maneira, sem me preocupar muito comigo. O poema a seguir, de Mário de Sá-Carneiro (1995), retrata metaforicamente essa ponte:

Eu não sou eu nem sou o outro,

Sou qualquer coisa de intermédio:

Pilar da ponte de tédio

Que vai de mim para o outro

Ao mesmo tempo, percebo que, na verdade, a resposta não deveria estar nem em mim e nem em meus alunos, mas, supostamente, no espaço existente entre ambos. Traduzindo: o foco não deve ser exclusivamente no professor 
nem exclusivamente no aluno, mas sim na aprendizagem: um meio-docaminho entre ambos, mas ao qual ambos têm acesso.

Esse distanciamento só foi permitido pela minha maior conscientização da relação entre planejar cursos e o processo de ensino-aprendizagem, tendo como pano de fundo a noção de gênero do discurso e sua importância no ensino de línguas para fins específicos.

As minhas reflexões revelam também as preocupações com a sala de aula, com os alunos, com os materiais, mas revela, ainda, uma preocupação intermediária, cujo foco reside principalmente no aluno. Ou seja, vejo o aluno como ponto de partida e de chegada, não levando em consideração todos os fatos relativos ao meu papel como professor e, principalmente, como ser humano: é como se eu me excluísse do processo e fizesse tudo em função do aluno.

Em suma, as respostas não estavam em mim, mas também não estavam em meus alunos, e a minha busca constante de respostas para diversas dúvidas é encontrada nas próprias experiências de sala de aula. Talvez daí o fato de eu me ver como um outro, o que me causa um certo estranhamento, pelo simples fato de eu me ver como um professor com uma bagagem ampliada, que não considerava anteriormente suas próprias experiências, o que me leva, de certa forma, a esse estranhamento inicial, até que consiga, com o vivenciar dessas novas experiências, assimilar esse novo aspecto de meu self.

Quanto aos cursos, foram, nessa fase, nomeados a partir do contexto profissional: inglês para atendimento a turistas no câmbio e inglês para atendimento telefônico a estrangeiros. Funcionando como a passagem para uma nova fase está o curso para entrevistas. Nessa fase, já estou no doutorado e utilizo o material desse curso, principalmente as produçóes do aluno gravadas em áudio, como material de análise para o planejamento de materiais de base sistêmico-funcional, como, por exemplo, o planejamento de atividades e tarefas em que incluo as noçóes de gênero e de registro, bem como as variáveis de campo, relações e modo, relacionados ao contexto de cultura e ao contexto de situação, elementos teóricos advindos da abordagem proposta por Halliday \& Hasan (1989).

A partir das reflexões sobre as experiências relacionadas a tais tarefas e de diversas leituras teóricas sobre as novas teorias que utilizo mas, principalmente, a partir da minha atuação no ensino instrumental, percebendo a utilização de tais conceitos de forma prática, pude entender a passagem para o terceiro momento. 


\section{(iii) Terceiro momento: o outro em mim}

No primeiro semestre de 2000, como aluno de doutorado do Programa de Estudos Pós-Graduados em Lingüística Aplicada e Estudos de Linguagem, da PUC-SP, participei do seminário de pesquisa 'A formação do professor de línguas', momento em que tive diversas oportunidades de refletir sobre a minha prática pedagógica e, conseqüentemente, sobre o meu papel como professor. Logo no início do curso, foi-nos solicitado completar, a partir de nossa prática, três afirmativas: O professor que sou, O professor que eu gostaria de ser e $O$ professor que eu temo ser. As minhas respostas foram as seguintes:

O professor que sou

Consciente do meu papel, na medida do possível, afinal ninguém é perfeito, tento me aprimorar a cada dia com base em reflexões, troca com colegas, cursos, congressos, workshops. Acho que o mais importante é saber o quê, como, para quem e onde se ensina, e, só a partir daí, desempenhar o seu papel naquele contexto.

O professor que eu gostaria de ser

Gostaria de ser cada vez mais consciente e mais aberto para que possa transformar o aprendizado de meus alunos em algo produtivo e motivador; acho que eu gostaria de ser o 'facilitador' em seu sentido teórico mais estrito, o que não é de todo fácil.

\section{O professor que eu temo ser}

Temo ser um professor controlador, que não leva em conta os interesses dos alunos e faz tudo em função daquilo que só ele acha que é correto, às vezes baseado em crenças arraigadas e conceitos extremistas e limitadores.

Durante o curso realizamos várias leituras, principalmente ligadas à reflexão (por exemplo: CONNELLY; CLANDININ, 1988; FULLAN, 1996; HANNAY; ROSS, 1997; DEWEY, 1938/1997; SCHÖN, 1983, 1987 e 1992; ZEICHNER, 1992 entre outros) e ao currículo (por exemplo: Silva, 1999-a e 1999-b, entre outros). As afirmaçóes acima passaram por várias elaborações, tanto em função da leitura dos textos como em função das discussōes em sala, do diário dialogado com a professora responsável pelo curso e da própria auto-observação. Ao final do curso, foi-nos solicitado que voltássemos aos nossos comentários e fizéssemos um levantamento das características lingüísticas que considerássemos fundamentais, e também que expandíssemos as idéias de forma a deixar claro o que queríamos dizer com elas, exemplificando se necessário. 
Eis parte da minha análise, inclusive com reflexões posteriores realizadas ao final daquele semestre:

Uma torta folhada. É isso que vejo ao analisar a materialidade discursiva do meu próprio discurso. Inúmeras características vêm à tona. E, quer queiramos, quer não, todas elas são permeadas pelo meu sistema de crenças. Comecemos pelo princípio: ao enunciar 'consciente do meu papel', já estou pressupondo que existe um papel que deve ser desempenhado pelo professor e, conforme vou explicitando as outras características, é como se as várias outras camadas fossem despontando, tal qual uma torta, onde várias camadas formam um todo e, cada camada, cada uma das partes que formam o todo traz consigo suas particularidades, seus sabores próprios, os ingredientes que os formaram e tornaram possível aquela consistência.

Posso considerar, na verdade, essas reflexões como o passo mais importante no terceiro momento de meu contínuo experiencial: a passagem de professor a course designer. Observo, no trecho acima, a preocupação em justificar o que digo através de termos como 'materialidade discursiva', pois foi nesse período que entrei em contato com as teorias e pesquisas qualitativas. Existe, de minha parte, uma certa relutância em aceitar-me como agente de meu próprio universo. Esse fato é corroborado por outra das questóes pertencentes ao final do curso sobre a formação de professores:

Para concretizar a visão do professor que você gostaria de ser indique, exemplificando, que ações você precisaria tomar (isto é, o que e como eu ensinaria, o que mudaria se eu ensinasse).

Se observarmos a minha resposta, veremos que ela revela uma fase de passagem para o terceiro momento em meu contínuo experiencial. Vejamos:

Creio que o caminho para tornar-me o professor que gostaria de ser é continuar a seguir as trilhas que estou seguindo, tentando cada vez mais conhecer-me como pessoa para que eu me conheça cada vez mais como professor. Essa foi a grande tônica do curso: sempre pensei no aluno e no que poderia fazer para que seu aprendizado fosse o mais agradável e proveitoso possível. Eu levava os fatores pessoais muito pouco em consideração, ou seja, não tinha noções muito claras sobre o panorama pessoal ou o panorama profissional, nem tinha uma preocupação tão grande com os diferentes tipos de reflexão ou o papel da experiência em minha prática. Agora posso dizer que isso tudo é muito mais consciente, o que torna mais fácil seguir os caminhos em direção ao 
professor que eu gostaria de ser, o que é resumido por Underhill (1999, p.140) na conclusão de seu artigo: "Facilitation does not allow me just to work on my students 'out there; it also requires me to work on myself 'in here'”, que será exatamente o meu objetivo daqui por diante.

Parece que finalmente eu havia me descoberto, e declaro isso no final de meu texto, justificando por escrito o meu objetivo de trabalhar com a minha própria existência, como o percurso relatado no seguinte poema (PESSOA, 1960, p.181):

Conta a lenda que dormia

Uma Princesa encantada

A quem só despertaria

Um Infante, que viria

De além do muro da estrada.

Ele tinha que, tentando,

Vencer o mal e o bem,

Antes que, já libertado,

Deixasse o caminho errado

Por o que à Princesa vem.

A Princesa Adormecida,

Se espera, dormindo espera.

E orna-lhe a fronte esquecida,

Verde, uma grinalda de hera.

Longe o Infante, esforçado,

Sem saber que intuito tem,

Rompe o caminho fadado.

Ele dela é ignorado.

Ela para ele é ninguém.

Mas cada um cumpre o Destino -

Ela dormindo encantada,

Ele buscando-a sem tino

Pelo processo divino

Que faz existir a estrada.

E, se bem que seja obscuro

Tudo pela estrada fora,

E falso, ele vem seguro,

$E$, vencendo estrada e muro,

Chega onde em sono ela mora. 
E, inda tonto do que houvera,

À cabeça, em maresia,

Ergue a mão, e encontra hera,

E vê que ele mesmo era

A princesa que dormia

O poema traduz perfeitamente a significação de meu terceiro momento profissional: percorro diversos caminhos, saio constantemente em busca de respostas, enfrento diversas batalhas, vou da teoria à prática e da prática a teoria um sem-número de vezes para descobrir algo que estava em mim mesmo.

De nada adiantaria eu desenvolver as mais diferentes tarefas para os mais diferentes fins enquanto eu não parasse para me observar e ver que todo o trabalho que eu desenvolvia tinha como ponto de partida e como ponto de chegada a minha própria existência, a minha percepção do mundo.

Referindo-me aos cursos esquematizados no Quadro 2, o curso para entrevistas representa o marco na passagem para essa nova fase, funciona como o fechamento de um ciclo, de uma fase na qual me encontro absolutamente consciente do meu papel como profissional de ensino instrumental e como course designer. A grande diferença aqui é a constante preocupação com o aluno e com o seu desempenho na língua estrangeira e se estou desempenhando com eficiência o papel de despertar a percepção do aluno.

O curso para entrevistas traz consigo, ainda, o fechamento de um outro ciclo, que se encerra com os cursos para atendimento a turistas no câmbio e para atendimento telefônico a estrangeiros, que foram ministrados em Brasília, ${ }^{3}$ de onde voltei com a cabeça repleta de idéias e com a bagagem marcadamente aumentada, tanto em seu sentido real quanto figurado: foi uma grande quantidade de materiais preparados para os cinco grupos ministrados em Brasília, e a troca de experiências com os alunos sobre suas impressões a respeito do curso foi muito enriquecedora.

Foi a partir daí que eu realmente percebi que um curso de inglês pode ser ministrado sem um material didático escolhido a priori. Pelo contrário: a experiência mostrou que o curso pode mostrar-se mais eficiente quando os materiais são preparados de acordo com as necessidades sentidas pelos alunos à medida que o curso vai se desenvolvendo e utilizando materiais do próprio contexto profissional dos alunos, adicionando significatividade ao aprendizado.

\footnotetext{
${ }^{3}$ Foram cinco os cursos ministrados em Brasília. Os outros três não compõem essas experiências, pois eram cursos de leitura instrumental e optei por trabalhar apenas os cursos de produção oral.
} 
Volto, nessa fase, a nomear os cursos a partir da profissão dos alunos que dele participarão. Diferentemente do primeiro momento, minha preocupação agora é com a identidade do aluno e com a sua identificação com o curso como evento comunicativo e fator de interação social: a minha percepção é a de que, a partir do momento que o aluno percebe que o material que utilizará tem o foco na sua área profissional, terá uma motivação maior e trabalhará de forma mais envolvente para atingir seus objetivos.

Minha preocupação, aqui, é mais social: preocupo-me com o papel social dos gêneros discursivos e com o discurso em si, que funcionará como fator de integração entre os participantes do curso. O gênero discursivo tornará possível a sua integração em novos eventos comunicativos, exercendo um impacto, por outro lado, em sua identidade construída na sala de aula.

É gratificante para o professor perceber a satisfação dos alunos em desenvolver exercícios envolvendo seus próprios nomes, seus departamentos, fatos sobre suas vidas e outras informações que trazem significado para o seu aprendizado. Uma simples mudança de postura: centrar o aprendizado na experiência. Uma simples mudança, devo acrescentar, que leva muito tempo, basta tomarmos como exemplo o meu percurso: somente após diversas experiências é que pude chegar a essa conclusão. Logo, outra conclusão a que chego é a de que mudar nossas crenças é algo que leva tempo. Por outro lado, não sei se posso dizer que cheguei a uma conclusão, pois, na verdade, não houve uma conclusão, mas uma nova percepção.

\section{A essência do fenômeno}

Ao observar o meu percurso retrospectivamente, e após buscar as significações em meus três momentos profissionais, paro, finalmente, para voltarme à essência do fenômeno para o qual busco explicações: o planejamento de cursos instrumentais orais com base em gêneros do discurso para alunos iniciantes.

Compreender a essência do fenômeno significa, como apontam Martins \& Bicudo (1989, p.77), "tomar o fenômeno seriamente diante dos olhos e estudá-lo de maneira sistemática para poder vir a compreender o objeto na sua intenção total, na sua essência, e não apenas na sua representação". A compreensão está baseada, assim, nas descrições das experiências vividas e dos significados que delas se extraem. Ao dizer que estou interessado em um fenômeno, isso deve ser traduzido da seguinte maneira: coloco o fenômeno em suspensão, coloco-o 'entre parênteses' para que possa compreendê-lo. 
O planejamento de cursos instrumentais, dessa forma, revela-se uma tarefa multifacetada, um fenômeno presente no dia-a-dia de inúmeros professores, não só de inglês instrumental, como foi o caso dos cursos referidos aqui, mas de professores de diversos idiomas em diversos contextos. É um fenômeno que existe em alguns casos e contextos, portanto, como parte da tarefa de ensinar.

Alguns dos profissionais envolvidos no planejamento de cursos buscam subsídios no meio externo, principalmente através de livros que tratem de questôes de planejamento, ou através da própria experiência, ou ainda em colegas mais experientes, ou simplesmente na tentativa-e-erro: aplica-se um material planejado e verifica-se sua funcionalidade ou eficiência e, a partir do sucesso ou da falha, continua-se ou não a sua aplicação.

A essência de planejar cursos, portanto, desvelou-se para mim como uma tarefa de cunho social: é necessário que se conheçam os diferentes contextos nos quais as pessoas que necessitam o curso irão interagir e como os conhecimentos lingüísticos da língua estrangeira sobre a área em questão irão auxiliá-los no desempenho de suas atividades profissionais.

O conhecimento lingüístico requerido ao profissional na tarefa de planejar cursos, por seu turno, foi uma das facetas que mais me incomodou: a constante convivência com a insegurança em relação à língua estrangeira, com a adequação das palavras ao contexto, com seu cunho pragmático, a nãofamiliaridade com a área de atuação dos profissionais ou o desconhecimento do jargão profissional tais como, por exemplo, o aprendizado de todo o vocabulário dos itens de lavanderia, dos objetos manuseados pelas camareiras, dos cardápios utilizados pelos garçons, dos aspectos profissionais das diferentes áreas apreendidos na interação com os alunos-profissionais em diferentes campos de atuação para os quais os cursos eram planejados, bem como o aprendizado com falantes nativos para a correta adequação da linguagem ao contexto de acordo com as diferentes necessidades e os diferentes profissionais para os quais os cursos foram planejados.

Vivenciei o fenômeno em sua intenção total, na sua essência. Através das histórias que contei e das descriçôes, passei a compreender o fenômeno em seu modo peculiar, em cada uma de suas nuances, em todas as suas qualidades particulares e próprias.

Olhar para esse fenômeno hoje é assumi-lo como uma experiência consciente e não como a representação de uma tarefa. Esse aspecto leva a um posicionamento crítico em relação à abordagem aqui utilizada, principalmente pelos vários desafios, percalços, experiências e tarefas a serem enfrentadas pelo 
pesquisador em sua prática de pesquisa que culmina na apresentação de resultados que possam ser partilhados com outros pesquisadores e que também possam ser vistos por outros olhares.

No âmbito mais amplo da pesquisa qualitativa, uma abordagem de cunho heurístico-fenomenológico-hermenêutico está no caminho do que sugere Rajagopalan (2003), no que concerne o repensar do binômio teoria/ prática, pois a postura crítica reside exatamente na recusa desse binômio. A essência do fenômeno aqui apresentado, bem como a metodologia utilizada para que se chegasse a sua essência, cujo princípio encontra-se exatamente numa interrogação e não numa definição, vai ao encontro dessa recusa ao racionalismo, que prega que a prática deve suceder a teoria.

Os princípios da pesquisa qualitativa e os caminhos pelos quais se enveredam os estudos no campo da Lingüística Aplicada sugerem uma revisão do que se tem feito na área, encaminhando os estudos para uma postura mais crítica (RAJAGOPALAN, 2003, 2006), ou a sugestão de Moita Lopes (2006, p. 23) de uma Lingüística Aplicada indisciplinar, que vá "além da tradição de apresentar resultados de pesquisa para os pares", é necessário um diálogo mais amplo, tanto na transdisciplinaridade como outras teorizaçôes. Como afirma Moita Lopes (2006, p.23):

são necessárias teorizações que dialoguem com o mundo contemporâneo, com as práticas sociais que as pessoas vivem, como também desenhos de pesquisa que considerem diretamente os interesses daqueles que trabalham, agem etc. no contexto de aplicação.

A busca pela essência do fenômeno de planejar cursos instrumentais por mim relatada tem exatamente esse cunho: o de contribuir, através de minha prática no contexto em que atuo, com outros colegas que desempenhem as mesmas tarefas e delas possam usufruir, utilizá-las e recontextualizá-las em suas práticas. Além disso, o diálogo com outras teorias, como aquele aqui estabelecido a partir da aplicação dos conceitos da heurística, fenomenologia e hermenêutica e seu diálogo com a pesquisa qualitativa em Lingüística Aplicada, leva-nos, também, a reconsiderar os modos como o conhecimento é produzido na área.

A abordagem utilizando experiências vividas não apresenta, dessa forma, nenhuma maneira nova ou uma nova metodologia, mas, simplesmente, um outro olhar para se vislumbrar um fenômeno. 


\begin{abstract}
Drawing on the concept of experiential continuum (DEWEY, 1938/ 1997), I report on lived experiences (van MANEN, 1990) of designing oral production courses in languages for specific purposes for real beginners based on discourse genres, mapping my professional experience and my transformation from a teacher to a course designer, based on the design of nine ESP courses developed over a five-year period. To report on these experiences, qualitative research methods of a heuristic-phenomenological-hermeneutic nature are adopted so as to reach the so-called phenomenological reduction (HUSSERL, 1973, 2000).

KEY-WORDS: lived experiences, ESP course design, heuristic-phenomenologichermeneutic approach
\end{abstract}

\title{
Referências bibliográficas
}

ANDRADE, C.D. No meio do caminho. In: Reunião - 10 livros de poesia de Carlos Drummond de Andrade. Rio de Janeiro: Livraria José Olympio Editora, 1974. 280 p.

BICUDO, M.A.V. Fenomenologia: confrontos e avanços. São Paulo: Cortez Editora, 2000. 167 p.

BRUNER, J. Atos de significação. Porto Alegre: Artes Médicas, 1997. 130 p.

CONNELLY, F. M.; CLANDININ, D. J. Teachers as curriculum planners: narratives of experience. New York/Toronto: Teachers College Press, 1988.

CORETH, E. Questôes fundamentais de hermenêutica. São Paulo: EPU, Editora Pedagógica e Universitária Ltda./Editora da Universidade de São Paulo, 1973. 202 p.

DEWEY, J. Experience and education. New York: Touchstone, 1938/1997. 171 p.

FULLAN, M. G. Turning systemic thinking on its head. Phi Delta Kappan. p. 420-423, Febr. 1996.

GADAMER, H-G. Hermenêutica como filosofia prática. Rio de Janeiro: Tempo Brasileiro, 1983. $731 \mathrm{p}$.

HALLIDAY, M.A.K.; HASAN, R. Language, context, and text. aspects of language in a social-semiotic perspective. Oxford: Oxford University Press. 1989. 126 p. HANNAY, L.M.; ROSS, J. A. Initiating secondary school reform: the dynamic relationship between restructuring, reculturing, and retiming. Educational Administrative Quarterly, v. 33, supplement, p. 576-603, 1997.

HEKMAN, S.J. Hermenêutica e sociologia do conhecimento. Lisboa: Edições 70 , 1986. 286 p.

HUSSERL, E. The idea of phenomenology. The Hague: Martinus Nijhoff, 1973. $60 \mathrm{p}$. 
HUSSERL, E. Investigaçôes lógicas. São Paulo: Nova Cultural. 2000. 224 p. (Coleção Os Pensadores).

HUSSERL, E. Meditações cartesianas: introdução à fenomenologia. São Paulo: Madras. 2001. 173 p.

KLEINING, G.; WITT, H. The qualitative heuristic approach: a methodology for discovery in psychology and the social sciences. Rediscovering the method of introspection as an example. Forum: Qualitative Social Research [On-line Journal], 1(1), 2000. Disponível em: <http://www.qualitative-research.net/fqstexte/1-00/1-00kleiningwitt-e.pdf>. Acesso em: 1 abr. 2007.

KLEINING, G. \& WITT, H. Discovery as basic methodology of qualitative and quantitative research. Forum: Qualitative Social Research [On-line Journal], 2(1). 2001. Disponível em: <http://www.qualitative-research.net/fqs-texte/101/1-01kleiningwitt-e.htm>. Acesso em: 1 abr. 2007.

LESTER, S. An introduction to phenomenological research. 1999. Disponível em: <http://www.devmts.demon.co.uk/resmethy.pdf>. Acesso em: 1 abr. 2007.

MARTINS, J. Um enfoque fenomenológico do currículo: educação como poiésis. São Paulo: Cortez Editora, 1992. 142 p.

MARTINS, J.; BICUDO, M. A. V. A pesquisa qualitativa em psicologia. São Paulo: Educ/Editora Moraes, 1989.

MASINI, E.S. Enfoque fenomenológico de pesquisa em educação. In: FAZENDA, I. (Org.). Metodologia da pesquisa educacional. São Paulo: Cortez Editora, 1989. p. 59-67.

MOITA LOPES, L.P. (Org.). Por uma lingüistica aplicada indisciplinar. São Paulo: Parábola Editorial. 2006. 279 p.

MOREIRA, D.A. O método fenomenológico na pesquisa. São Paulo: Thomson Pioneira, 2002. $152 \mathrm{p}$.

MOUSTAKAS, C. Heuristic research: design, methodology, and applications. Newbury Park: Sage, 1990. 130 p.

MOUSTAKAS, C. Phenomenological research methods. Thousand Oaks: Sage Publications, 1994. 192 p.

PESSOA, F. Eros e Psiquê. In: Cancioneiro - Fernando Pessoa: obra poética, volume único. Rio de Janeiro: Editora Nova Aguilar, 1960/1999. 842 p.

PUCHKIN, V.N. Heurística: a ciência do pensamento criador. Rio de Janeiro: Zahar Editores, 1976. 182 p.

RAJAGOPALAN, K. Por uma lingüistica crítica: linguagem, identidade e a questão ética. São Paulo: Parábola Editorial. 2003. 143 p. 
RAJAGOPALAN, K. Repensar o papel da lingüística aplicada. In: MOITA LOPES, L.P. (Org.). Por uma lingüistica indisciplinar. São Paulo: Parábola Editorial, 2006. p. 149-168.

REZENDE, A.M. Concepção fenomenológica da educação. São Paulo: Cortez Editora, 1990. 96 p.

RICOUER, P. Do texto à acção. Porto: Rés Editora, 1989. 407 p.

SÁ-CARNEIRO, M. Obra completa. Rio de Janeiro: Nova Aguilar, 1995. 1101 p.

SCHLEIERMACHER F.D.E. Hermenêutica - arte e técnica da interpretação. Petrópolis: Vozes, 1999. 102 p.

SCHÖN, D. The reflective practitioner: how professionals think in action. New York: Basic Books, 1983. 374 p.

SCHÖN, D. Educating the reflective practitioner: toward a new design for teaching and learning in the professions. San Francisco: Jossey-Bass Publishers, 1987. 355 p. SCHÖN, D. The theories of inquiry: Dewey's legacy to education. Curriculum Inquiry, v. 22, n. 2, p. 119-139, 1992a.

SCHÖN, D. A formação dos professores: novas perspectivas baseadas na investigação sobre o pensamento do professor. In: NÓVOA, A. (Ed.). Os professores e sua formação. Lisboa: Publicações Dom Quixote. 1992b. p. 77-91. van MANEN, M. Researching lived experience - human science for an action sensitive pedagogy. Ann Harbor: The Althouse Press, 1990. 202 p.

VIAN JR. O. Conceito de gênero e análise de textos de vídeos institucionais. 1997. 129 f. Dissertação (Mestrado) - Pontifícia Universidade Católica de São Paulo, 1997.

VIAN JR., O. O planejamento de cursos instrumentais de produção oral com base em gêneros do discurso: mapeamento de experiências vividas e interpretações sobre um percurso. 2002. 227 f. Tese. Doutorado em Lingüística Aplicada e Estudos da Linguagem) - Programa de Estudos Pós-Graduados em Lingüística Aplicada e Estudos da Linguagem. Pontifícia Universidade Católica de São Paulo, 2002. VIAN JR. O. O ensino de inglês instrumental para negócios, a lingüística sistêmicofuncional e a teoria de gênero/registro. The ESPecialist, v. 24, n. 1, p. 1-16, 2003. ZEICHNER, K. Novos caminhos para o practicum: uma perspectiva para os ano 90. In: NÓVOA, A. (org.). Os professores e a sua foramção. Lisboa: Publicações Dom Quixote. 1992. 